Introduction: Triple-negative breast cancers (TNBCs) - which lack the expression of estrogen receptor (ER), progesterone receptor (PR) and human epidermal growth factor receptor 2 (HER-2) - have no established markers that can be used for prognostic stratification. As adiponectin has been previously implicated in a more aggressive phenotype of primary breast cancer, we explored the relation between adiponectin immunohistochemical expression and prognosis in TNBCs.

Material and methods: Immunohistochemical staining for adiponectin was performed in 38 TNBC patients. Disease-free survival (DFS) and overall survival (OS) served as the main outcome measures.

Results: Of the 38 TNBC patients, $18(47 \%)$ had negative and $20(53 \%)$ positive adiponectin immunohistochemical expression. We did not find any significant association between adiponectin immunohistochemical expression and the baseline characteristics. In addition, there were no associations between adiponectin immunohistochemical expression and prognosis. Conclusions: Although our results suggest that adiponectin immunohistochemical expression is not of prognostic significance in TNBCs, further studies are warranted to determine the role of this adipokine in breast cancer biology.

Key words: triple-negative breast cancer, adiponectin, immunohistochemistry, prognosis.

Contemp Oncol (Pozn) 2014; 18 (1): 34-38 DOI: $10.5114 /$ wo.2014.40454

\section{Lack of prognostic significance of adiponectin immunohistochemical expression in patients with triple- negative breast cancer}

\author{
Erdem Cubukcu ${ }^{1}$, Omer Fatih Olmez ${ }^{1}$, Ozkan Kanat $^{1}$, Selva Kabul ${ }^{2}$, \\ Mustafa Canhoroz ${ }^{1}$, Nilufer Avci ${ }^{1}$, Mustafa Hartavi ${ }^{3}$, Adem Deligonul', \\ Sinem Çubukçu $u^{3}$ Osman Manavoglu ${ }^{1}$
}

${ }^{1}$ Department of Medical Oncology, Uludag University Medical School, Bursa, Turkey 2Department of Pathology, Uludag University Medical School, Bursa, Turkey ${ }^{3}$ Department of Internal Medicine, Uludag University Medical School, Bursa, Turkey

\section{Introduction}

Basal-like breast cancers negative for the expression of estrogen receptor (ER), progesterone receptor (PR) and human epidermal growth factor receptor 2 (HER-2) amplification are known as triple-negative breast cancers (TNBCS). Triple-negative breast cancers are rare (15-20\% of all breast cancers) [1-3] and tend to behave aggressively [4]. Triple-negative breast cancers are not only characterized by particularly poor outcomes [5, 6] but they are also refractory to currently available targeted therapy (tamoxifen, aromatase inhibitors, trastuzumab) used to treat other breast cancers [7]. Because targeted treatment of TNBCs remains a major challenge, chemotherapy remains the only systemic therapy currently available for TNBCs [8]. However, disappointing outcomes of standard chemotherapy with TNBCs [1-3] might be related to poor efficacy of standard chemotherapy regimens in unselected patients [7]. Future research strategies in TNBCs should prioritize the identification of potential biomarkers significantly associated with prognosis [9]. The individualization of patient treatment through biomarker-based risk stratification may help to improve outcomes by maximizing efficacy whilst lowering toxicity $[10,11]$.

Adiponectin is the most abundant adipokine secreted from adipose tissue, and its synthesis is reduced in obesity, insulin resistance, and type 2 diabetes [12, 13]. Besides metabolic derangements, several lines of evidence have suggested a potential role of adiponectin in the biology of breast cancer, including cell proliferation, angiogenesis, and insulin regulation [14-16]. Adiponectin has been suggested to exert anti-carcinogenic effects in mammary cancer [15]. However, based on existing immunohistochemical data in patients with primary breast cancer, patients with invasive carcinoma have higher positive rates of adiponectin expression compared with patients with ductal carcinoma in situ [16]. Interestingly, high adiponectin expression was significantly correlated with smaller tumor size [16]. Because there are crosstalks between obesity, the metabolic syndrome, adiponectin and breast tumorigenesis [3], the study of adiponectin in relation to TNBCs seemed worthy of investigation. In addition, adiponectin has been shown to inhibit the proliferation of human breast cancer cell lines [17-20]. Unfortunately, no information is currently available on the association between adiponectin immunohistochemical expression and prognosis in patients with TNBCs.

Because of the lack of established prognostic markers in TNBCs, in this study we sought to investigate the prognostic significance of adiponectin immunohistochemical expression with respect to disease-free survival (DFS) and overall survival (OS) in a group of homogeneously treated TNBC pa- 
tients. In the present report, immunohistochemistry was used because several previous studies have shown the prognostic utility of immunohistochemical markers in several different malignancies and disease conditions [21-23].

\section{Material and methods}

Patients with TNBCs were prospectively enrolled in the Department of Oncology at Uludag University Medical Center, Bursa, Turkey. Estrogen receptor status and progesterone receptor status were taken as positive if more than $10 \%$ of tumor cells showed staining. Immunohistochemical score of 3+ or fluorescence in situ hybridization+ for HER2 was accepted as HER2 positivity [24]. We prospectively identified a total of 38 patients with TNBCs who underwent surgery between January 2004 and September 2011. In all participants, the expression of ER, PR, and HER-2 was immunohistochemically negative in paraffin-embedded tissue specimens. None of these cancer patients received treatment prior to surgery. The patients underwent complete or partial mastectomies with fully resected axillary dissections. Patients received anthracycline- and taxane-containing chemotherapy if the tumor was node positive.

The clinicopathological characteristics such as menopausal state, age, and tumor invasiveness were evaluated based on pathological reports and medical records. Prognostic factors including tumor size, nodal status, and histological grade were evaluated in all participants. Lesion staging was assessed according to the sixth edition of the American Joint Committee on Cancer (AJCC) staging manual for breast cancer. Tumor necrosis was defined as the presence of necrosis of any dimension in a section of invasive cancer. Histologic grading was performed using the criteria of Bloom and Richardson [25]. The study protocol was approved by the institutional review committee of the Uludag University Medical Center, Bursa, Turkey. All patients gave written consent.

\section{Adiponectin immunohistochemical expression}

Immunohistochemistry was performed on formalin-fixed, paraffin-embedded breast cancer tissue as previously described, with slight modifications. Adiponectin expression levels were analyzed in keeping with previous methodology by an expert pathologist who was blinded to the patient's clinical records [16]. The staining was scored as 0 if no cancer cells were reactive, 1 if staining was weakly positive in $<2 / 3$ of cancer cells, or strongly positive in $<1 / 3$ of cancer cells, and 2 if staining was weakly positive in $>2 / 3$ of cancer cells, or strongly positive in $>1 / 3$ of cancer cells. Finally, adiponectin immunohistochemical staining in breast cancer tissue of TNBCs was classified as negative (score 0 ) or positive (score 1 and 2; Fig. 1).

\section{Statistical analysis}

The sample size was calculated by using GraphPad StatMate version 2.0 for Windows (GraphPad Software, San Diego, CA, USA). Our study had 95\% power to detect a hazard ratio of death of 0.310 with a significance level (alpha) of 0.05 (two-tailed) between patients with positive (vs. negative) adiponectin immunohistochemical expression. Variables were expressed as means \pm standard deviation, medians (lower quartile-upper quartile) or as numbers (percentages) if categorical. Correlations were tested using Spearman's correlation coefficient. Disease-free survival was defined as freedom from breast cancer recurrence. Overall survival was defined as freedom from breast cancer death or other causes of death. We assessed the association of each risk factor with DFS and OS by multivariable Cox proportional hazard regression analysis. The multivariable Cox model included all the demographic, clinical, and biochemical characteristics of the study participants. The appropriateness of the proportional hazards assumption was verified using graphical methods and tested as per Grambsch and Therneau [26]. The assumption of linearity for the Cox models was examined through visual inspection, and no violation was found. Hazard ratios (HRs) and their 95\% confidence intervals (Cls) were calculated with the estimated regression coefficients and their standard errors in the Cox models. Cumulative survival rates of breast cancer cases were analyzed by the Kaplan-Meier method. The differences of cumulative survival were assessed using the log-rank method. Statistical analyses were performed using SPSS software (version 14.0,
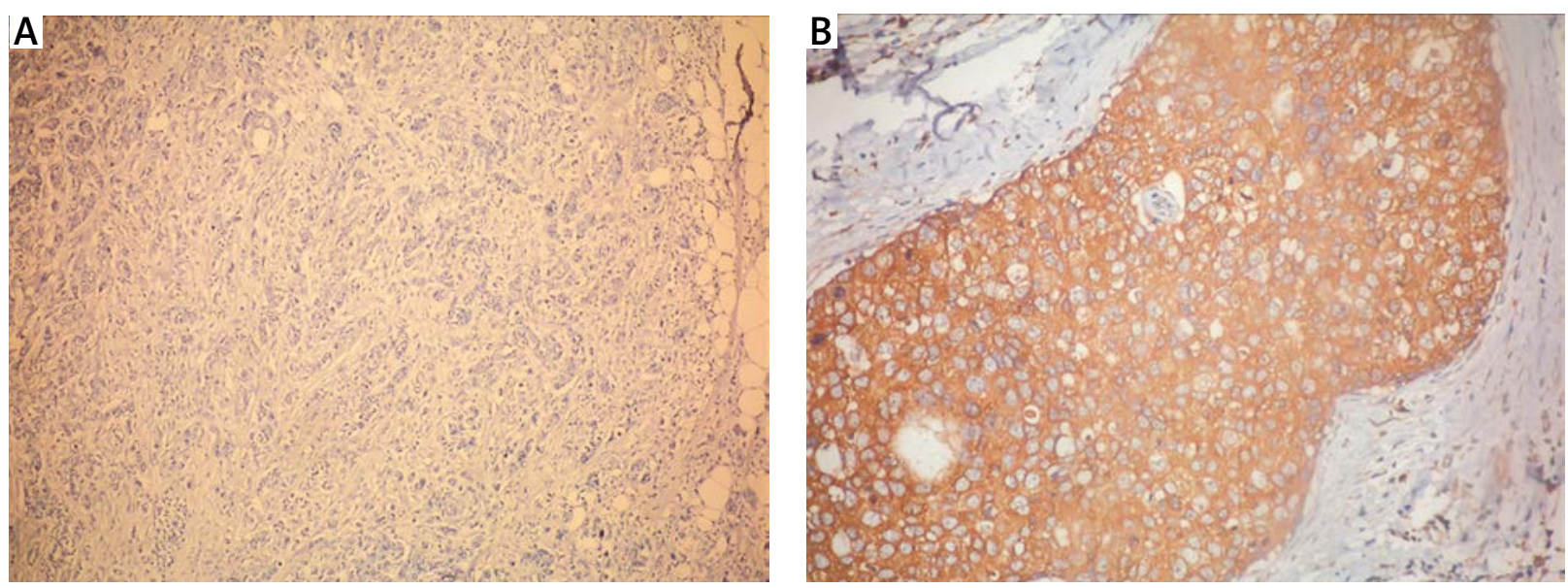

Fig. 1. Negative (A) and positive (B) immunostaining of adiponectin in triple-negative breast cancer specimens; magnification $\times 100$ 
SPSS Inc., Chicago, IL, USA). Two-tailed P-values $<0.05$ were considered statistically significant.

\section{Results}

The main characteristics of the TNBC patients at baseline are shown in Table 1. Of the 38 study participants, 34 had invasive ductal carcinoma, 2 metaplastic carcinoma, and the remaining 2 other forms of carcinoma. The axillary lymph node status was as follows: pNO in 19 patients, pN1 in 12 patients, pN2 in 5 patients, and pN3 in 2 patients. Three patients were carriers of mutations in BRCA1/2. Nineteen patients (50\%) underwent total and 19 (50\%) partial mastectomies. Besides chemotherapy, 26 patients (68\%) received radiotherapy. The patients were followed up for a median of 30 months (maximum $=110$ months).

\section{Adiponectin immunohistochemical expression and prognosis}

Of the 38 TNBC patients, 18 (47\%) had negative and 20 (53\%) positive adiponectin immunohistochemical expression in breast cancer specimens. We did not find any significant association between adiponectin immunohistochemical expression and the baseline characteristics of the study participants, including age, postmenopausal status, the presence of necrosis, tumor size, grade, and stage (Table 2).

The median progression-free survival (PFS) in the study participants was 24 months (17-40 months), whereas the median OS was 29 months (20-48 months). Categorization of the patient population according to adiponectin immunohistochemical expression did not reveal any statistically significant difference in terms of either OS ( $p=0.90)$ or DFS ( $p=0.27$, Fig. 2 ). The results of multivariable Cox regression analysis (Table 3 ) indicated that tumor grade and axillary lymph node status were the two main prognostic independent predictors in our TNBC series.

\section{Discussion}

The significance of adiponectin immunohistochemical expression in patients with breast cancer has recently been

Table 1. Characteristics of the patient population $(n=38)$

\begin{tabular}{|cc|}
\hline Age (years) & $50 \pm 11$ \\
Postmenopausal status & $17(48 \%)$ \\
Presence of necrosis & $21(55 \%)$ \\
Tumor size & \\
$<2 \mathrm{~cm}$ & $7(18 \%)$ \\
$2-5 \mathrm{~cm}$ & $28(74 \%)$ \\
$>5 \mathrm{~cm}$ & $3(8 \%)$ \\
Tumor grade & \\
1 & $5(13 \%)$ \\
2 & $10(26 \%)$ \\
3 & $23(61 \%)$ \\
Tumor stage & \\
1 & $4(11 \%)$ \\
2 & $24(63 \%)$ \\
3 & $10(26 \%)$
\end{tabular}

Data are means \pm standard deviation or number of patients (\%). given its first epidemiological support. In this regard, Jeong et al. [16] have shown that high adiponectin expression in tissue specimens may be associated with breast cancer invasiveness. The present study is the first prospective survey addressing the association between adiponectin immunohistochemical expression and prognosis in a series of patients with TNBCs. The prognosis of women with TNBCs is significantly poor compared to women with other forms of breast cancer [1-3]. Therefore, there is an urgent need of biomarker tools to improve the prognostic stratification of this high-risk group [8, 9]. Unfortunately, our data do not support an association of the adiponectin immunohistochemical expression with either PFS or OS in patients with TNBCs. In contrast, in our cohort of TNBCs we found that tumor grade and axillary lymph node status were the only two variables significantly associated with prognosis. The results on tumor grade were in keeping with previous studies analyzing TNBC cohorts [9]. In particular, a large study of 6,370 TNBC patients produced similar results in terms of histological grade [27]. Recent years have also witnessed increased awareness of the prognostic significance of lymph node status to stratify survival outcomes in TNBCs [28]. Although putatively less prominent lymph node involvement in TNBCs has been reported, it is clear from our and previous data that TNBC patients with axillary lymph node involvement experience a significant decrease in their outcome compared with those without nodal spread [28].

Adiponectin is a fat-derived hormone whose reduction plays central roles in obesity-linked diseases [29]. The deregulation of adiponectin in the setting of obesity and its impact on cancer progression and metastasis has been actively investigated in recent years due to the pleiotropic actions of this molecule. Notably, adiponectin has been linked to the metabolic syndrome, which in turn has been recently associated with TNBCs $[3,13,28]$. The potential role of adiponectin in TNBCs is a topic of considerable interest because of the lack of any established biomarkers in this clinical entity [1-3]. However, we failed to detect a prognostic significance on outcomes in this group of patients, suggesting that adiponectin is not useful in risk stratification of TNBCs. Our negative results do not appear to result from lack of power of our study as shown by our sample size calculation. Moreover, we did not identify any significant association between adiponectin immunohistochemical expression and the baseline charac-

Table 2. Correlation analysis of adiponectin immunohistochemical expression with the general characteristics of TNBC patients

\begin{tabular}{|lcc|}
\hline Parameter & $\begin{array}{c}\text { Spearman's } \\
\text { correlation } \\
\text { coefficient }\end{array}$ & $P$-value \\
\hline Age & -0.14 & 0.38 \\
\hline Postmenopausal status & 0.27 & 0.10 \\
\hline Presence of necrosis & -0.19 & 0.21 \\
\hline Tumor size & -0.08 & 0.62 \\
\hline Tumor grade & -0.22 & 0.15 \\
\hline Tumor stage & -0.26 & 0.09 \\
\hline
\end{tabular}


Table 3. Predictors of disease-free survival and overall survival (Cox regression analysis) in TNBC patients

\begin{tabular}{|c|c|c|c|c|c|c|c|c|}
\hline \multirow{3}{*}{ Variable } & \multicolumn{4}{|c|}{ Disease-free survival } & \multicolumn{4}{|c|}{ Overall survival } \\
\hline & \multicolumn{2}{|c|}{ univariable } & \multicolumn{2}{|c|}{ multivariable } & \multicolumn{2}{|c|}{ univariable } & \multicolumn{2}{|c|}{ multivariable } \\
\hline & $\begin{array}{c}\mathrm{HR} \\
(95 \% \mathrm{Cl})\end{array}$ & $p$ & $\begin{array}{c}\text { HR } \\
(95 \% \mathrm{Cl})\end{array}$ & $p$ & $\begin{array}{c}\mathrm{HR} \\
(95 \% \mathrm{Cl})\end{array}$ & $p$ & HR $(95 \% \mathrm{Cl})$ & $p$ \\
\hline Age & $\begin{array}{c}1.07 \\
(0.98-1.18)\end{array}$ & 0.21 & $\begin{array}{c}1.09 \\
(0.94-1.19)\end{array}$ & 0.45 & $\begin{array}{c}1.09 \\
(0.94-1.14)\end{array}$ & 0.43 & $\begin{array}{c}1.10 \\
(0.93-1.23)\end{array}$ & 0.57 \\
\hline $\begin{array}{l}\text { Postmenopausal } \\
\text { status }\end{array}$ & $\begin{array}{c}2.18 \\
(0.94-5.07)\end{array}$ & 0.11 & $\begin{array}{c}2.05 \\
(0.90-4.78)\end{array}$ & 0.38 & $\begin{array}{c}3.33 \\
(0.78-8.60)\end{array}$ & 0.57 & $\begin{array}{c}2.95(0.51- \\
6.35)\end{array}$ & 0.65 \\
\hline $\begin{array}{l}\text { Presence of } \\
\text { necrosis }\end{array}$ & $\begin{array}{c}1.04 \\
(0.91-1.17)\end{array}$ & 0.45 & $\begin{array}{c}1.07 \\
(0.93-1.28)\end{array}$ & 0.32 & $\begin{array}{c}1.00 \\
(0.94-1.07)\end{array}$ & 0.99 & $\begin{array}{c}1.09(0.90- \\
1.19)\end{array}$ & 0.84 \\
\hline Tumor size & $\begin{array}{c}0.78 \\
(0.31-1.97)\end{array}$ & 0.51 & $\begin{array}{c}0.85 \\
(0.42-2.15)\end{array}$ & 0.69 & $\begin{array}{c}1.32 \\
(0.55-3.85)\end{array}$ & 0.34 & $\begin{array}{c}1.42(0.50- \\
3.79)\end{array}$ & 0.37 \\
\hline Tumor grade & $\begin{array}{c}3.22 \\
(1.75-7.44)\end{array}$ & 0.007 & $\begin{array}{c}2.71 \\
(1.02-7.89)\end{array}$ & 0.03 & $\begin{array}{c}1.48 \\
(1.11-3.60)\end{array}$ & 0.01 & $\begin{array}{c}1.24(1.03- \\
2.42)\end{array}$ & 0.04 \\
\hline Tumor stage & $\begin{array}{c}1.94 \\
(0.96-2.89)\end{array}$ & 0.39 & $\begin{array}{c}2.12 \\
(0.93-2.97)\end{array}$ & 0.44 & $\begin{array}{c}1.97 \\
(0.90-2.99)\end{array}$ & 0.24 & $\begin{array}{c}2.12 \\
(0.89-3.22)\end{array}$ & 0.45 \\
\hline $\begin{array}{l}\text { Axillary lymph } \\
\text { node status }\end{array}$ & $\begin{array}{c}3.80 \\
(1.57-9.18)\end{array}$ & 0.003 & $\begin{array}{c}3.93 \\
(1.34-7.14)\end{array}$ & 0.01 & $\begin{array}{c}4.28 \\
(1.11-12.35)\end{array}$ & 0.02 & $\begin{array}{c}4.55 \\
(1.02-11.77)\end{array}$ & 0.05 \\
\hline $\begin{array}{l}\text { BRCA1/2 } \\
\text { mutations }\end{array}$ & $\begin{array}{c}1.13 \\
(0.92-1.58)\end{array}$ & 0.29 & $\begin{array}{c}1.11 \\
(0.94-1.66)\end{array}$ & 0.27 & $\begin{array}{c}1.27 \\
(0.85-1.62)\end{array}$ & 0.71 & $\begin{array}{c}1.39 \\
(0.81-1.85)\end{array}$ & 0.84 \\
\hline $\begin{array}{l}\text { Type of } \\
\text { mastectomy }\end{array}$ & $\begin{array}{c}0.79 \\
(0.69-1.11)\end{array}$ & 0.68 & $\begin{array}{c}0.73 \\
(0.55-1.89)\end{array}$ & 0.75 & $\begin{array}{c}0.94 \\
(0.61-1.44)\end{array}$ & 0.55 & $\begin{array}{c}1.09 \\
(0.69-1.67)\end{array}$ & 0.68 \\
\hline Adiponectin + & $\begin{array}{c}1.68 \\
(0.68-2.70)\end{array}$ & 0.34 & $\begin{array}{c}1.32 \\
(0.76-2.39)\end{array}$ & 0.41 & $\begin{array}{c}1.25 \\
(0.67-3.14)\end{array}$ & 0.89 & $\begin{array}{c}1.33 \\
(0.59-3.67)\end{array}$ & 0.93 \\
\hline
\end{tabular}

teristics of the study participants, including age, postmenopausal status, the presence of necrosis, tumor size, grade, and stage. These data seem to suggest that adiponectin immunohistochemical expression is not directly correlated with the clinicopathological characteristics of TNBCs. In any case, further studies are warranted to determine the role of adiponectin in breast cancer biology.

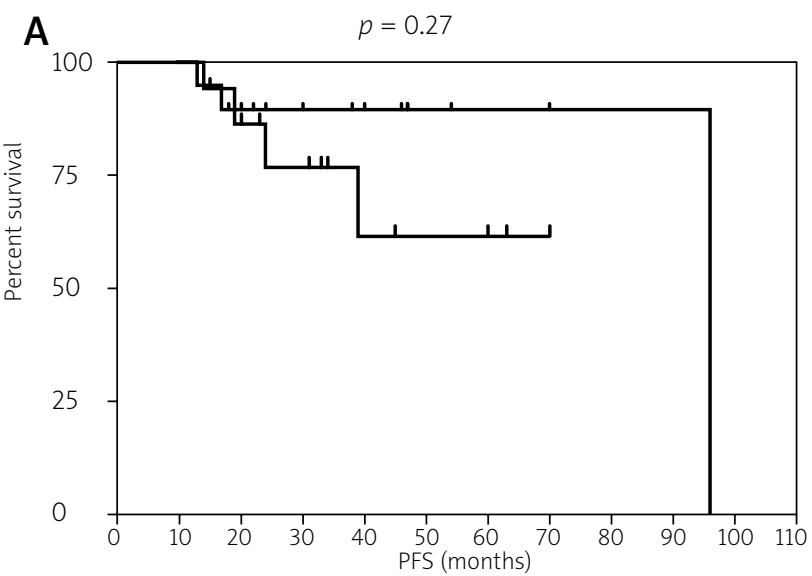

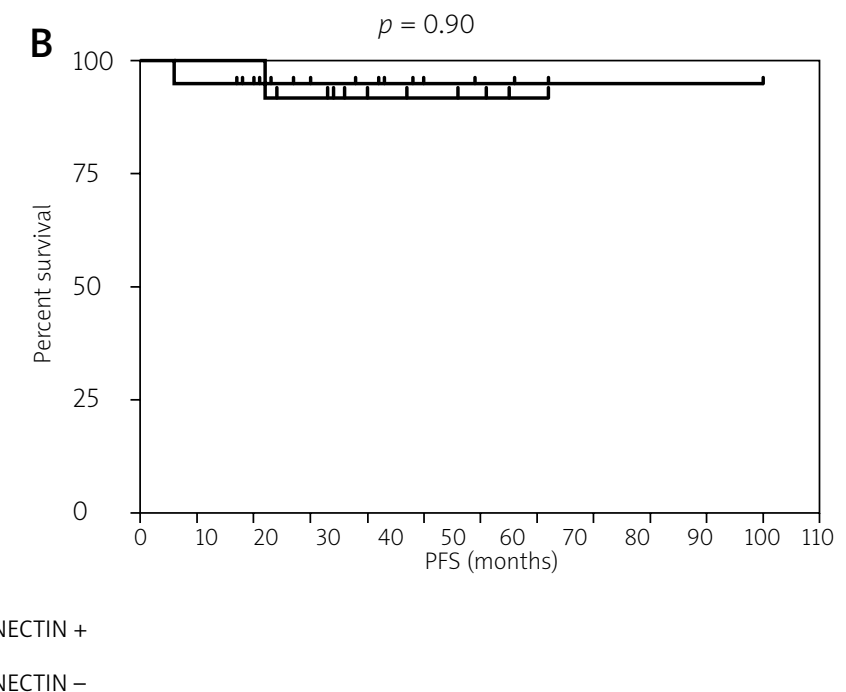

Some limitations of our study merit consideration. First, our population consisted exclusively of Turkish subjects without ethnic diversity. Therefore, extrapolation of any conclusions from the present investigation may be incorrect and future studies in different clinical cohorts are needed to confirm and expand our findings. Second, we did not measure circulating adiponectin levels in plasma

Fig. 2. Kaplan-Meier plots for disease-free survival (A) and overall survival (B) according to adiponectin immunohistochemical expression 
because of financial constraints. Therefore, we cannot exclude that plasma adiponectin levels may have a role in the risk assessment of TNBC patients. Future studies are needed to shed more light on this important issue. Notably, low levels of circulating adiponectin have been reported in women with endometrial cancer, in men with prostate cancer, and in patients suffering from colorectal cancer [29]. Importantly, Duggan et al. [30] recently reported an association between reduced levels of adiponectin and increased breast cancer mortality in breast cancer survivors.

In summary, we did not find any significant association between adiponectin immunohistochemical expression and baseline characteristics of TNBC patients. In addition, there were no associations between adiponectin immunohistochemical expression and prognosis. Although our results suggest that adiponectin expression in cancer specimens is not of prognostic significance for TNBCs, further studies are warranted to determine the future potential of this molecular approach in primary breast cancer.

The authors declare no conflict of interest.

\section{References}

1. Oakman C, Moretti E, Pacini G, Santarpia L, Di Leo A. Triple negative breast cancer: a heterogeneous subgroup defined by what it is not. Eur J Cancer 2011; 47: 370-2.

2. Hudis CA, Gianni L. Triple-negative breast cancer: an unmet medical need. Oncologist 2011; 16: 1-11.

3. Davis AA, Kaklamani VG. Metabolic syndrome and triple-negative breast cancer: a new paradigm. Int J Breast Cancer 2012; 2012: 809291.

4. de Ruijter TC, Veeck J, de Hoon JP, van Engeland M, Tjan-Heijnen VC. Characteristics of triple-negative breast cancer. I Cancer Res Clin Oncol 2011; 137: 183-92.

5. Foulkes WD, Smith IE, Reis-Filho JS. Triple-negative breast cancer. N Engl J Med 2010; 363: 1938-48.

6. Chacón RD, Costanzo MV. Triple-negative breast cancer. Breast Cancer Res 2010; 12: 1-3.

7. Yagata H, Kajiura Y, Yamauchi H. Current strategy for triple-negative breast cancer: appropriate combination of surgery, radiation, and chemotherapy. Breast Cancer 2011; 18: 165-73.

8. Teng YH, Thike AA, Wong NS, Tan PH. Therapeutic targets in triple negative breast cancer - where are we now? Recent Pat Anticancer Drug Discov 2011; 6: 196-209.

9. Albergaria A, Ricardo S, Milanezi F, Carneiro V, Amendoeira I, Vieira D, Cameselle-Teijeiro J, Schmitt F. Nottingham Prognostic Index in triple-negative breast cancer: a reliable prognostic tool? BMC Cancer 2011; 11: 299.

10. Nanda R. "Targeting" triple-negative breast cancer: the lessons learned from BRCA1-associated breast cancers. Semin Oncol 2011; 38: 254-62

11. Constantinidou A, Jones RL, Reis-Filho JS. Beyond triple-negative breast cancer: the need to define new subtypes. Expert Rev Anticancer Ther 2010; 10: 1197-213.

12. Cui J, Panse S, Falkner B. The role of adiponectin in metabolic and vascular disease: a review. Clin Nephrol 2011; 75: 26-33.

13. Matsuzawa Y. Adiponectin: a key player in obesity related disorders. Curr Pharm Des 2010; 16: 1896-901.

14. Schäffler A, Schölmerich J, Buechler C. Mechanisms of disease: adipokines and breast cancer - endocrine and paracrine mechanisms that connect adiposity and breast cancer. Nat Clin Pract Endocrinol Metab 2007; 3: 345-54.

15. Jardé T, Perrier S, Vasson MP, Caldefie-Chézet F. Molecular mechanisms of leptin and adiponectin in breast cancer. Eur J Cancer 2011; 47: 33-43.
16. Jeong YJ, Bong JG, Park SH, Choi JH, Oh HK. Expression of leptin, leptin receptor, adiponectin, and adiponectin receptor in ductal carcinoma in situ and invasive breast cancer. J Breast Cancer 2011; 14: 96-103.

17. Kang JH, Lee YY, Yu BY, Yang BS, Cho KH, Yoon DK, Roh YK. Adiponectin induces growth arrest and apoptosis of MDA-MB-231 breast cancer cell. Arch Pharm Res 2005; 28: 1263-9.

18. Dos Santos E, Benaitreau D, Dieudonne MN, Leneveu MC, Serazin V, Giudicelli Y, Pecquery R. Adiponectin mediates an antiproliferative response in human MDA-MB 231 breast cancer cells. Oncol Rep 2008; 20: 971-7.

19. Grossmann ME, Nkhata KJ, Mizuno NK, Ray A, Cleary MP. Effects of adiponectin on breast cancer cell growth and signaling. Br J Cancer 2008; 98: 370-9.

20. Arditi JD, Venihaki M, Karalis KP, Chrousos GP. Antiproliferative effect of adiponectin on MCF7 breast cancer cells: a potential hormonal link between obesity and cancer. Horm Metab Res 2007; 39: 9-13.

21. Huszno J, Mrochen-Domin I, Zembala-Nożyńska E, Tukiendorf A, Lange D, Nowara E. Mucin secretion activity of gastric cancer as a prognostic factor: a clinicopathological analysis. Wspolczesna Onkol 2012; 16: 159-64.

22. Szczerkowska-Dobosz A, Lange M, Roszkiewicz J, Sobjanek M, Biernat W. Cutaneous-limited Degos disease - benign variant or distinctive clinical entity? Post Dermatol Alergol 2011; 1: 71-4.

23. Kula Z, Jóźwicki W, Zegarski W. Benign mesocolon schwannoma in PET/CT and immunohistochemistry assessement: a case report. Wspolczesna Onkol 2012; 16: 360-2.

24. Gown AM. Current issues in ER and HER2 testing by IHC in breast cancer. Mod Pathol 2008; 21 Suppl 2: 8-15.

25. Bloom HJ, Richardson WW. Histological grading and prognosis in breast cancer; a study of 1409 cases of which 359 have been followed for 15 years. Br J Cancer 1957; 11: 359-77.

26. Grambsch PM, Therneau TM. Proportional hazards tests and diagnostics based on weighted residuals. Biometrika 1994; 81: 515-26.

27. Bauer KR, Brown M, Cress RD, Parise CA, Caggiano V. Descriptive analysis of estrogen receptor (ER)-negative, progesterone receptor (PR)-negative, and HER2-negative invasive breast cancer, the socalled triple-negative phenotype: a population-based study from the California cancer Registry. Cancer 2007; 109: 1721-8.

28. Dent R, Trudeau M, Pritchard KI, et al. Triple-negative breast cancer: clinical features and patterns of recurrence. Clin Cancer Res 2007; 13: 4429-34

29. Izadi V, Farabad E, Azadbakht L. Serum adiponectin level and different kinds of cancer: a review of recent evidence. ISRN Oncol 2012; 2012: 982769

30. Duggan C, Irwin ML, Xiao L, et al. Associations of insulin resistance and adiponectin with mortality in women with breast cancer. J Clin Oncol 2011; 29: 32-9.

\section{Address for correspondence}

\section{Dr Erdem Cubukcu}

Department of Oncology

Uludag University Medical School

Nilufer, 16059, Bursa, Turkey

tel. +9022429513 56, fax +902244428166

e-mail: erdemcubukcu@uludag.edu.tr

Submitted: 10.01.2013

Accepted: 18.07.2013 